\title{
Tiempo vivido y tiempo recordado de don Francisco de Montejo Xiu: "Título de tierras de Maní" en la Historia
}

The Lost and Found Times of Don Francisco de Montejo Xiu: The "Título de tierras de Mani" in History

Temps perdu et temps retrouvé de Don Francisco de Montejo Xiu : «Les titres fonciers de Mani » dans l'histoire

\section{Tsubasa Okoshi Harada}

\section{OpenEdition}

\section{Journals}

Edición electrónica

URL: http://journals.openedition.org/jsa/15433

DOI: 10.4000/jsa.15433

ISSN: $1957-7842$

Editor

Société des américanistes

Referencia electrónica

Tsubasa Okoshi Harada, "Tiempo vivido y tiempo recordado de don Francisco de Montejo Xiu: "Título de tierras de Maní" en la Historia », Journal de la société des américanistes [En línea], Maya times | 2017, Publicado el 31 diciembre 2017, consultado el 01 mayo 2019. URL : http://journals.openedition.org/ jsa/15433 ; DOI : 10.4000/jsa.15433 


\title{
Tiempo vivido y tiempo recordado de don Francisco de Montejo Xiu: "Título de tierras de Maní" en la Historia
}

\author{
Tsubasa OKoshi HaradA*
}

\begin{abstract}
Este trabajo analiza a través de un estudio histórico y comparativo de los "Títulos de tierras de Maní" cómo don Francisco de Montejo Xiu, último halach uinic del cúuchcabal de Maní, intentó construir una nueva entidad política en el marco del régimen colonial. Después de su fallecimiento, los pueblos de indios aprovecharon su figura como fundador del tiempo-espacio en el que habitaban para legitimar la posesión de sus territorios. El pasado recordado en estos "títulos", a fin de cuentas, existía siempre en relación con el presente y la distancia entre esos dos momentos era más corta de lo que imaginamos. [Palabras claves: títulos de tierras, tiempoespacio, mayas coloniales, Maní, don Francisco de Montejo Xiu, maya, Mesoamérica, México, Yucatán.]
\end{abstract}

The Lost and Found Times of Don Francisco de Montejo Xiu: The "Titulo de tierras de Mani" in History. This paper presents a study of how Don Francisco de Montejo Xiu, the last halach uinic of the cúuchcabal of Maní, attempted to construct a new political entity with deep pre-Hispanic roots within the framework of colonial society. It is based on a historical and comparative analysis of the "Titulos de tierras de Mani". After his death, the indigenous pueblos de indios took advantage of his renown as a founder in their own space-time to legitimate their land claims. The past recorded in these "Maní Land Titles" ultimately owed its existence to its relationship to the experienced present, and the perceived distance between the two space-times was much shorter than what one might imagine. [Key words: land titles, time-space, colonial Maya, Maní, Don Francisco de Montejo Xiu, Maya, Mesoamerica, Mexico, Yucatan.]

Temps perdu et temps retrouvé de Don Francisco de Montejo Xiu : "Les titres fonciers de Mani » dans l'histoire. À partir d'une analyse historique et comparative des «titres fonciers de Mani », cet article analyse comment don Francisco de Montejo Xiu, dernier halach uinic du cúuchcabal de Mani, tenta d'établir, dans le cadre de la société coloniale, une nouvelle entité politique aux racines

* Instituto de Investigaciones Filológicas, Universidad Nacional Autónoma de México / Departamento de Estudios Hispánicos, Universidad de Estudios Extranjeros de Kyoto [t_okoshi@kufs.ac.jp]. 
profondément préhispaniques. Après sa mort, les pueblos de indios utilisèrent son image de fondateur de l'espace-temps dans lequel ils vivaient, pour légitimer la possession de leurs terres. Le passé mémorisé dans les «titres fonciers de Mani » existait bien en relation avec le présent vécu, et la distance perçue entre les deux espaces-temps était beaucoup plus courte que ce que l'on pourrait croire. [Mots-clés : titres fonciers, espace-temps, mayas coloniaux, Maní, don Francisco de Montejo Xiu, Maya, Mésoamérique, Mexique, Yucatan.]

\section{Introducción}

Para los mayas de las Tierras Bajas del norte, el fin de la campaña militar hispana en el sector noroccidental de la Península de Yucatán significó el prólogo de una etapa ulterior de reacomodo en todos los aspectos y niveles de su vida. No obstante, la situación política de la sociedad colonial recién fundada no era nada favorable para llevar a cabo tales reacomodos. Entre los encomenderos y los frailes franciscanos existían notables conflictos de interés con respecto al trato hacia los indígenas. Los primeros deseaban explotar la mano de obra como único recurso viable y los segundos querían protegerlos de este abuso. Para allanar esta disputa y reformar el gobierno de acuerdo con las Leyes Nuevas dictadas en España, en 1552 la Audiencia de los Confines envió al oidor Lic. Tomás López Medel como visitador. Una vez llegado a Yucatán asumió en seguida el gobierno de la provincia y se dedicó a legislar, dictando ordenanzas para la vida social y política de la misma, "ajustando la de los españoles y dando nuevas formas a la de los indios, consagrando especial interés a corregir los abusos que cometían aquéllos y aboliendo las costumbres ruines de éstos" (Rubio Mañé 1945, p. xxxiv). Respecto a este último, la idea central de sus disposiciones converge, a decir de Hanks (2010, p. 2-5), en el término de "reducción" que consiste en: i) construir un espacio ordenado a través de la política de congregación, ii) la conversión de los indígenas en cristianos con la finalidad de que vivieran en la "policía cristiana", y finalmente, iii) elaborar una lengua "simplificada en su sucinta regla" para establecer comunicación con los mayas. El objetivo de las ordenanzas del Lic. López Medel era, en otras palabras, introducir a los indígenas al mundo "civilizado" por medio de la lengua maya "reducida" y a través de la imposición de nuevos principios occidentales sobre la tenencia de la tierra y la vida en "policía cristiana".

Sus consecuencias, que fueron mencionadas por Rubio Mañé como "revolucionarias" por haber transformado radicalmente la vida de Yucatán (ibid.), pueden evaluarse desde diversos ángulos y en este trabajo discutiré temas que atañen a la noción indígena de tiempo y su manejo, siempre con base en el análisis histórico y comparativo de los "Títulos de tierras", en especial aquel conjunto de distintas versiones agrupadas bajo la denominación de "Título de tierras de Maní (1557)" (Solís Alcalá 1949, p. 347-353; "Crónica de Maní”, 
MS; Stephens 1963, II, p. 172-174; Quezada y Okoshi Harada 2001, p. 55-65). Es decir, el objetivo consiste en dilucidar cómo los mayas fueron adoptando la nueva idea sobre el tiempo en sus escritos desde una temprana etapa, pero a la vez, lo colocaron dentro del marco del concepto tradicional del mismo, en el que el "pasado" claramente expresado con el sistema calendárico europeo llegaría a cobrar una noción completamente distinta a la española ${ }^{1}$. Especial énfasis se dará a la figura de don Francisco de Montejo Xiu, el último halach uinic del cúnchcabal ${ }^{2}$ de Maní, quien elaboró el título de su jurisdicción y a cuyo nombre fueron preparados varios títulos de tierras de los pueblos de indios.

\section{La fundación y creación del nuevo espacio-tiempo: intención de don Francisco de Montejo Xiu}

La política de congregación se inició ya en 1546 en la comarca de la villa de Campeche dirigido por fray Luis de Villalpando (López Cogolludo 1957, lib. v, cap. v, p. 254). En 1548 la Corona emitió una Cédula Real dirigida al virrey Antonio de Mendoza, en donde se ordena viese la conveniencia de que se iniciara este proyecto (Quezada 1993, p. 83). Pero la inestable situación política de Yucatán no se lo permitió a los franciscanos sino hasta después de 1552, año en que el Lic. López Medel había determinado su necesidad en sus Ordenanzas. Esta política alteró sustancialmente el patrón de asentamiento tradicional, pues más allá de centralizar las comunidades dispersas en determinados pueblos, cada uno de los mismos debía contar con un trazo reticular alrededor del espacio central, así como con un lindero que demarcara los límites de su extensión espacial, para que los pueblos de indios tuvieran sus propios "territorios".

No obstante, los primeros documentos escritos en lengua maya yucateca con caracteres latinos, elaborados hacia la década de 1550, no eran títulos de tierras de estos pueblos individuales de indios, sino que se trataba de las jurisdicciones de los halach uinicob de don Juan Cocom, mejor conocido como Na Chi Cocom, y de don Francisco de Montejo Xiu. Esto se debió a la situación política particular de la gobernación de Yucatán, donde hasta principios de la sexta década del siglo XVI, los españoles permitieron a los gobernantes mayas continuar con el ejercicio de su poder, manteniendo sus entidades políticas de origen prehispánico hasta su muerte que ocurriría en la sexta década de tal centuria.

Esta circunstancia ofreció a los dos ambiciosos gobernantes, Na Chi Cocom de Sotuta y Ah Kukum Xiu o don Francisco de Montejo Xiu de Maní una

1. Para la discusión lingüística detallada sobre el mismo tema, véanse los trabajos de Hanks (2000 [1987], p. 133-164; 2010, p. 291-295).

2. Cúuchcabal se refiere a una entidad política prehispánica de carácter jurisdiccional en que una casa señorial ejercía su poder asentado en un noh cah "gran pueblo" o capital. Se usaba siempre anteponiéndolo al topónimo de dicho noh cah como: u cúuchcabal Motul. 
coyuntura que no podían dejar pasar. En especial, para Na Chi Cocom era una oportunidad singular para rectificar la actitud hostil que había mantenido durante el periodo de la conquista. Era un hombre perspicaz y vislumbró la manera más adecuada para sobrevivir en el nuevo régimen. Tomó la decisión de recibir el bautismo y ya como Juan Cocom colaboró con los españoles ${ }^{3}$ : participó de forma por demás activa en la política de congregación. Pero, por otra parte, él se mostraba ansioso por marcar, legitimar y hacer patente su jurisdicción como una entidad política indígena dentro del régimen colonial. Como muchos señores indígenas de otras regiones mesoamericanas de ese entonces, los Cocom apostaron por convertirse en súbditos del rey de España para salvaguardar sus privilegios y el derecho a ejercer su poder.

Respecto a Ah Kukum Xiu (don Francisco de Montejo Xiu) la situación era completamente diferente. Desde el inicio de la conquista, los Xiu fueron fieles aliados de los españoles, por lo que su participación en la política colonial era activa sobremanera y ejemplar para los ojos de los invasores hispanos. No obstante, como su homólogo $\mathrm{Na}$ Chi Cocom, él aspiraba a continuar con su señorío.

Pese a la trayectoria política opuesta de ambos gobernantes durante la campaña militar, los dos aprovecharon la coyuntura de la política de congregación e intentaron delimitar la extensión de su dominio y la registraron sobre el papel europeo para posteriormente ser reconocida por la autoridad española. Ya hacia 1555 don Juan Cocom elaboró su "Título", sin llegar a un acuerdo comunal sobre el deslinde con otros señores de los pueblos colindantes (Roys 1939, p. 422-433). Esto provocó numerosas disputas sobre los límites de varios pueblos de indios que perduraría hasta finales de la época colonial (Roys op. cit.). Don Francisco de Montejo Xiu se dio cuenta de que el sector noroeste de su jurisdicción estaba registrado como si cayera en el dominio de don Juan, por lo que en 1557 preparó su propio "Título" obteniendo el consentimiento de gran número de los señores adyacentes.

Una vez logrado el consenso respecto al deslinde de la jurisdicción de estos señores, se inicia la siguiente etapa que corresponde nada menos que a la elaboración de los títulos escritos sobre papel europeo. Durante ese proceso los escribanos indígenas adoptaron el formulismo diplomático hispano, requisito indispensable para que el documento tuviera validez jurídica y uno de sus elementos fue la fecha tópica y crónica para precisar el momento y lugar de su producción ${ }^{5}$.

3. De acuerdo con fray Diego de Landa (1938, cap. xi, p. 21), don Juan Cocom era "muy familiar de" él y como era un "hombre de gran reputación y muy sabio en sus cosas, y en las naturales bien sagaz y entendido", "le contó muchas antigüedades", e inclusive le había mostrado "un libro que fue de su abuelo".

4. Si bien la copia de este documento elaborada a principios del siglo XVII registra la fecha de 1545, el contexto histórico, referido en líneas arriba, apunta claramente que ésta no es real.

5. Al respecto, véase también Hanks (ibid.; 2010, p. 285-289). 
Respecto al registro de la fecha crónica, por ejemplo, en la "Memoria de la distribución de los montes", una versión del "Título de tierras de Maní"6, recogido en los Papeles de los Xiu de Yaxá, se aprecia la siguiente frase nominal (Quezada y Okoshi Harada op. cit., p. 65): "tu ho[la]hunpiz u kinil u agosto ti hab 1557 años (en quince días de agosto del año de 1557)". Por otra parte, en la "Crónica de Maní" se lee (MS, f. 2v): “tu lahunpiz u kinil u julio ichil yabil de 1596 años (a 10 de julio del año de 1596)". Ambos ejemplos demuestran una mezcla del sistema numérico-calendárico de origen prehispánico e hispano, en que los amanuenses mayas continuaban manejando el sistema numeral maya para la cuenta de los días mientras que habían adoptado las demás unidades calendáricas españolas (mes y año).

Este formato de la fecha crónica híbrida mantuvo su vigencia hasta mediados del siglo XVII. Luego, a partir de la segunda mitad de la misma centuria hasta finales de la época colonial los escribanos indígenas optaron por utilizar el sistema español en su totalidad, como por ejemplo: "helel en 9 de septiembre 1657 años" (Quezada y Okoshi Harada op. cit., p. 81). Este cambio se percibe primeramente en los documentos notariales, es decir, en aquellos papeles escritos por los escribanos de los cabildos indígenas con fines administrativos y legales (Restall 1997, p. 231; Hanks 2010, p. 285), y casi un siglo después se apreciaría la misma transición en otros textos cuasinotariales destinados a

6. Como se ha mencionado líneas arriba, existen cuatro versiones diferentes del "Título de tierras de Maní", a saber: 1) la "Memoria de la distribución de los montes" que forma parte de los Papeles de los Xiu de Yaxá (Quezada y Okoshi Harada 2001, p. 55-65); 2) otra incluida en la "Crónica de Maní" (MS; Roys 1943, p. 173-194); 3) aquella versión que se encuentra en el Códice Pérez (Solís Alcalá 1949, p. 347-357); y finalmente, 4) la que John L. Stephens publicó parcialmente en 1843 (1963, I, p. 172-174). La "Memoria de la distribución de los montes" junto con los demás papeles administrativos y legales de los Xiu estuvieron resguardados hasta 1884 por la familia Xiu de Yotholín, Yucatán. Su último dueño fue don Bernabé Xiu (Quezada y Okoshi Harada op. cit., p. 19). Si bien no se sabe a ciencia cierta la fecha de su último traslado (copia), es muy probable que sea de la segunda mitad del siglo XVIII. Asimismo, debido a que a lo largo del texto se mantiene el discurso en tercera persona del singular y del plural, se supone que sea una copia más fiel al documento original de 1557. En tanto que la versión contenida en la "Crónica de Maní" contamos con informaciones más detalladas. En 1596 Ticul se encontraba en litigio con otro pueblo, por lo que mandó a su escribano, Francisco Cab, que fuera al archivo de Maní para sacar una copia del "Título de tierras de Maní" de 1557 con la finalidad de utilizarla para fundamentar sus reclamos. Posteriormente, este mismo escribano le agregó otro traslado de la sección inicial del "Título", y así se formó su propio título de tierras. Hacia 1642 al fundarse el pueblo de Nohcacab, su cabildo solicitó al de Ticul un traslado de este título y lo utilizó como su título de tierras. El documento actual es una copia del título del siglo XVII y fue utilizado en 1800 para la querella con Calkiní. La versión del Códice Pérez probablemente procede del pueblo de Pencuyut sin poder reconstruir la posible historia de su compilación hecha sobre el traslado del "Título de tierras de Maní" de 1557. El texto traducido al inglés por John L. Stephens es un fragmento en que se reproduce la parte principal de este "Título", y demuestra cierta semejanza con la versión de la "Memoria de la distribución de los montes". 
la lectura interna de la comunidad como el caso del libro de Chilam Balam de Chumayel, en el que se lee (Gordon ed. 1913, p. 81) por ejemplo: "hele en 20 de henero (sic) de 1782"'.

Sin embargo, esto de ninguna manera implica que en el mundo maya se utilizara única y exclusivamente el sistema calendárico español. En realidad, éste estaba yuxtapuesto con el de origen prehispánico basado en el sistema vigesimal y especialmente en los documentos cuasinotariales se mezclaba su empleo, siendo preponderante el autóctono. Al respecto, es emblemático el caso de don Juan Xiu Cimé de mediados del siglo XVII. Él nació en Yaxakumché, en el asiento de Oxkutzcab, como hijo primogénito de don Alonso Xiu, cacique y señor natural de dicho pueblo (Quezada y Okoshi Harada op. cit., p. 79). Estaba muy entregado a la carrera política en la gobernación de Yucatán: en 1644 fue designado como capitán de los indios flecheros de Oxkutzcab y al año siguiente como su gobernador. En 1667 fue trasladado a Maxcanú como gobernador y capitán de los indios flecheros (ibid., p. 47). Este brillante político indígena en el régimen colonial, regresando a casa, se dedicaba a: "hochah uchben hun hek [...] calacteres u kaba anates (copiar un antiguo papel que [estaba escrito en] caracteres, llamado anahte)" (ibid., p. 101). Dicho de otra manera, él trasladaba un libro de tipo Chilam Balam, en cuya página se podía leer frases como: "1542 años oxlahun kan tu hunte popi u hedzci cah españolesob ti Hoo cahciob [...] (1542 años, 13 Kan 1 Pop, se asentaron los españoles en Ho, [es decir] la poblaron)" (ibid., p. 100).

Por otra parte, contamos con varias evidencias documentales que señalan el manejo del sistema vigesimal a lo largo de la época colonial. Por ejemplo, en la cuenta de los regalos entregados a los participantes del deslinde de la jurisdicción de don Francisco de Montejo Xiu se había empleado de la manera siguiente: "laobi ti kami u canil / ti hohobak ti haa [...] yetel hohokal u hulil yayax tunich (Éstos recibieron sus presentes: cinco veces cuatrocientos [granos de cacao] cada uno, $[. .$.$] y cinco veintenas de piedras verdes enhilados cada$ uno)" (ibid., p. 57-58; "Crónica de Maní" MS, f. 1r). Por otra parte, en mayo de 1743 cuando se hizo una revisión del deslinde de los montes de Ebtún, Simón

7. En la sección de la "Memoria sobre la historia de Yucatán" de Chilam Balam de Chumayel, podemos encontrar una fecha escrita como (op. cit., p. 17): "hele en 20 de agosto ti yaabil de 1541", fecha muy temprana con un estilo que no corresponde al del siglo XVI. Es muy probable que este texto fuera elaborado en el siglo XVII o posteriormente. Por otra parte, es de señalar que el empleo del sistema calendárico europeo en los documentos notariales persistió a lo largo de la época colonial, mientras que a partir de la segunda mitad del siglo XVIII los intérpretes generales de la gobernación de Yucatán comenzaron a recurrir al estilo híbrido empleado por los escribanos indígenas del siglo XVI. Por ejemplo, al trasuntar la fecha de emisión del mandamiento del gobernador de Yucatán, el intérprete general Pedro Cervera la tradujo de la siguiente manera (Quezada y Okoshi Harada op. cit., p. 149): "uay ti Ho uaxacpel kinil yuil febrero de mil setesientos setenta y nueve años (Aquí en Ho / Mérida, a ocho días del mes de febrero de 1779 años)". 
Cen, el escribano del pueblo, anotó los nombres de los testigos-participantes con su edad de la manera que sigue: "Gaspal Dzib oxkal hab catac lahunpis yan ti; Andres Chi oxkal catac cap'el hab yan ti [...] (Gaspar Dzib, que tiene tres veintenas de años más diez; Andrés Chi, que tiene tres veintenas más dos años [...]" (Roys op. cit., p. 278-279). Finalmente, hacia 1815, Manuela Chan, vecina del pueblo de Ebtún, tuvo que pagar "ca kal peso (dos veintenas de pesos)" para la "compra" del monte del pueblo de Tzucmuc (ibid., p. 372-373).

Esta coexistencia de dos conceptos de origen distinto sobre el tiempo y el cálculo numérico en los documentos mayas coloniales también va de la mano con el concepto de espacio, en concreto con la referencia del lugar, "aquí (uay)", desde donde se produce el discurso. En la "Crónica de Maní" este término está empleado doce veces (MS, fs. 1r-2v) y en la "Memoria de la distribución de los montes" cuatro veces (Quezada y Okoshi Harada, op. cit.) y en el Códice Pérez dos veces (Solís Alcalá 1949) ${ }^{8}$. La variedad de estas expresiones se puede clasificar en dos grupos: i) la fecha tópica propiamente dicha, el formato español más común acompañado de la crónica: "Tu cahal Mani tu holahunpiz u kinil $u$ agosto ychil yaabil de 1557 años (en el pueblo de Maní, a 15 días de agosto del año de 1557)" ("Crónica de Maní" MS, f. 1r), e ii) indicación concreta del lugar de la elaboración del documento dentro del marco jerárquico del sistema político colonial. Este último, a su vez, con frecuencia se describe con el manejo de paralelismos como por ejemplo":

1. su hunmolcinah $u$ baob

2. ti multumut

3. ycnal halach uinic

4. don Francisco de Montejo Xiu

5. governador

6. uay ti noh cah Mani lae

1. tu cahal Sanct Miguel Mani

2. tu governacionil Yucatan

1. ti hunmolob

2. governadoresob

3. alcaldesob
Se reunieron
para acordar
junto al halach uinic
don Francisco de Montejo Xiu,
gobernador de
aquí del gran pueblo de Maní.

(Quezada y Okoshi Harada op. cit., p. 55)

En el pueblo de San Miguel Maní

de la gobernación de Yucatán

(“Crónica de Maní" MS, f. 2v)

Se reunieron

los gobernadores,

los alcaldes,

8. En cuanto a la versión registrada en Stephens (1963, II, p. 172-174) no se puede encontrar, aparentemente, ningún caso. Esto probablemente se debe a que en la traducción al inglés Stephens hubiera omitido esos "detalles" del texto maya por no ser relevantes para sus intereses.

9. Respecto a otros ejemplos así como su análisis detallado, véase Hanks (2000 [1987], p. 151-155). 

4. regidoresob
5. ti cabildo
6. uay ti audienía
7. ti noh cah Mani
8. tu tan halach uinic
9. don Francisco de Montejo Xiu
10. gobernador
11. uay ti cabeçera
12. ti noh cah Mani lae

\author{
[y] los regidores \\ del cabildo \\ aquí en la audiencia \\ del gran pueblo de Maní, \\ ante el halach uinic, \\ don Francisco de Montejo Xiu, \\ gobernador \\ de aquí de la cabecera, \\ de este gran pueblo de Maní. \\ (“Crónica de Maní” MS, f. 2v)
}

Esta notable insistencia de "aquí (uay)" puede ser interpretada como una reafirmación del marco espacio-temporal impuesto por la autoridad española en que vivía la nobleza maya (Hanks 2000 [1987], p. 155). Dicho de otra manera, "aquí (uay)" se refiere, en primer término, a un espacio creado y fundado por los españoles, cuya entidad política, es decir la gobernación de Yucatán, cuya capital era la ciudad de Mérida, y Maní formaba parte de los pueblos de indios incorporados a la misma como se observa en el mapa insertado en el libro de Chilam Balam de Chumayel (Figura 1).

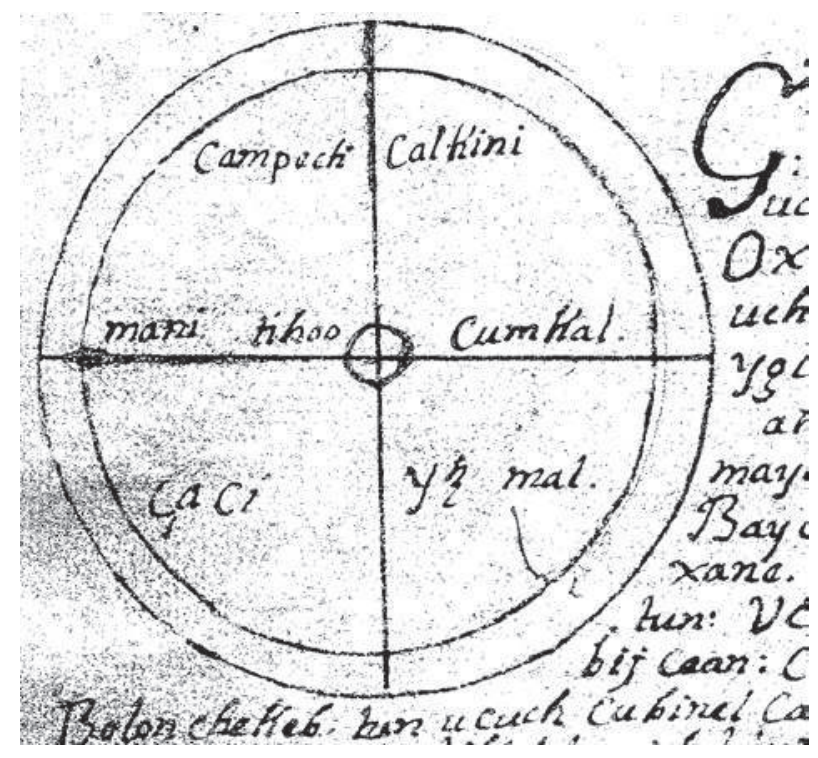

Fig. 1 - Mapa circular de la provincia de Yucatán (Gordon 1913, p. 67).

El manuscrito original del libro del "Chilam Balam de Chumayel" se encuentra en la Biblioteca de la Universidad de Princeton. 
No obstante, casi la mitad de los pasajes en que se aprecia esta voz "aquí (uay)" consiste en una repetición del mismo formulismo: halach uinic / don Francisco de Montejo Xiu / gobernador / uay ti (noh) cah Mani ${ }^{10}$, lo cual permite otra interpretación basada en la concepción maya del espacio. Una clave sería el manejo paralelo de los dos cargos que ocupaba este personaje: halach uinic y en relación con "aquí (uay)", en este caso Maní, asiento desde donde él ejercía su poder. El primero es de origen prehispánico y relaciona explícitamente a don Francisco con aquella facultad de ejercer su jurisdicción sobre todos los que lo reconocieran como gobernante supremo, quienes habitaban en una región con amplia extensión espacial. Mientras que como gobernador del cabildo indígena, cargo establecido en la segunda mitad del siglo XVI por la autoridad española, él encabezaba única y exclusivamente el cabildo y pueblo de Maní donde residía.

Otro elemento clave sería el hecho de que el topónimo (Maní) está referido en relación con el poder que ahí se asienta o viceversa, el poder está mencionado con su asiento. Para los mayas, un espacio nunca puede ser concebido de manera abstracta, sino que siempre estaba ligado con la persona que ejercía su poder sobre él. Por ejemplo, Na Chan Canul, gobernante de Calkiní, al hablar de la extensión de su jurisdicción decía que hasta la aguada de Tzemez Akal alcanzaba su poder, porque allí vivía Na May Tayú quien reconocía su soberanía (Okoshi Harada 2009, p. 64). De hecho, todos los topónimos que este gobernante indígena menciona eran asentamientos humanos o lugares donde "su gente" trabajaba. Por lo tanto, esta relación del hombre y su espacio tenía su raíz en la época prehispánica y a través de estos formulismos, el escribano quiso enfatizar justamente la intención de don Francisco de Montejo Xiu: registrar su jurisdicción dentro del espacio impuesto por la autoridad española.

Este acto de don Francisco no debe entenderse como una simple muestra de su destreza en el campo diplomático y político, ni tampoco en términos del espontáneo intento de "hacer sobrevivir su señorío" bajo el régimen español. Es más, se trataba de una decisión cuidadosamente diseñada, cuyo objetivo podría haber consistido en la "fundación-creación de una nueva entidad política indígena" o bien, en otras palabras, en la búsqueda de renovación de su señorío adaptándose al complejo sistema sociopolítico y religioso colonial, adoptando, a la vez, varios elementos discursivos hispanos en los suyos ${ }^{11}$. En ese proceso, se elaboró el "Título", donde confluyen las nociones y conceptos de origen diverso sobre espacio, tiempo y poder. Así, el "Título" de don Francisco de Montejo Xiu, si bien no cuenta con la parte correspondiente a los "mitos", se

10. En la "Crónica de Maní" se registran 5 de 12 casos, en la "Memoria de la distribución de los montes" 3 de 4, y en el Códice Pérez 1 de 2.

11. Véase el trabajo reciente de Hanks (2010), en el que este investigador expone de manera amplia sobre este tema. 
convertiría, como lo discutiremos en el siguiente inciso, en el escrito donde se narra el "origen" del espacio-tiempo de la ex-jurisdicción de los Xiu, cuyo fundador sería este gobernante maya.

\section{Hacia la "mitificación" de la figura de don Francisco de Montejo Xiu en los "títulos primordiales": creación del "origen"}

El ocaso del sueño de don Francisco de Montejo Xiu trajo consigo un cambio mucho más profundo de lo que sus pueblos dependientes jamás habían imaginado. Su desgracia comenzó en 1561 cuando fue acusado de emborracharse y forzar a las mujeres a acostarse con él. Declarado culpable en todas sus acusaciones, fue sentenciado a ser azotado, desterrado y fue suspendido su cacicazgo. Peor aún, al año siguiente también fue denunciado por haber participado en idolatría (Quezada 1993, p. 147; Quezada y Okoshi Harada, op. cit., p. 44). Si bien una vez liberado retomó las riendas de la política de su pueblo, a finales de la sexta década o a principios de la siguiente del siglo XVI falleció sin descendencia. La autoridad española no permitió a su sucesor, don Francisco, hijo de don Melchor Xiu, hermano de don Francisco de Montejo Xiu, sucederle en el cargo de halach uinic. Gaspar Antonio Chi Xiu ${ }^{12}$ fue designado como teniente de gobernador de toda esa entidad indígena, pero tanto el defensor de los naturales como los mismos indígenas no apoyaron tal nombramiento. De tal manera se desintegró esta entidad política de origen prehispánico, y cada uno de sus pueblos componentes tuvieron que comenzar a buscar la forma más adecuada para sobrevivir en la nueva etapa del régimen colonial. Sus posesiones territoriales tendrían que ser defendidas por ellos mismos y con ese fin necesitaban contar con un título que avalara el derecho ancestral sobre su espacio. De esta manera, a partir de 1591, tras la introducción de las composiciones de tierra así como la fundación del Juzgado de Indios en Mérida (Borah 1996, p. 353-354), a decir de Menegus Bornemann (1994, p. 208): "las comunidades de indios por voluntad propia, compusieron masivamente en los siglos XVII y XVIII sus tierras y, por otra parte, dieron origen a los llamados títulos primordiales de los pueblos".

Lo anterior de ninguna manera implicaba que todas las comunidades indígenas declararan la independencia rompiendo aquellos lazos sociopolíticos, económicos, religiosos y de parentesco que hasta ese entonces mantenían

12. Gaspar Antonio Chi Xiu, uno de los mayas yucatecos más conocidos del siglo XVI nació hacia 1531 en Maní como hijo de Ah Kin Chi cuya esposa era Ix Kukil Xiu. Nacido en el seno de la nobleza de la familia Xiu, recibió su primera educación como tal y posteriormente fue educado por los franciscanos. Era informante del fray Diego de Landa así como de los demás españoles contándoles la historia y las costumbre prehispánicas de su propio pueblo, aparte de ser intérprete general de la Gobernación de Yucatán. Al respecto, véase Okoshi Harada (2001, p. 59-72). 
con las demás. En realidad, esos nexos no se rompían con facilidad, lo cual se observa también en el manejo de los primeros "Títulos" elaborados por don Juan Cocom (1545) y don Francisco de Montejo Xiu (1557). Los "originales" de dichos documentos estaban conservados en los archivos de Sotuta y Maní, capitales de las entidades políticas del mismo nombre, aun después de su desintegración ${ }^{13}$. A estos acervos documentales, a lo largo de la época colonial, los representantes de los pueblos que en la época prehispánica estaban subordinados a estas dos casas señoriales, así como otros colindantes, acudían constantemente para su consulta. Inclusive solicitaban su traslado para utilizarlos en algún litigio en que se veían involucrados, o bien con la finalidad de elaborar sus propios títulos.

A continuación, analizaremos de manera más concreta este fenómeno histórico tomando como ejemplo las cuatro versiones del "Título" atribuido a don Francisco de Montejo Xiu. Por cada una de éstas, que indicaremos por su abreviatura, a saber: la de los Papeles de los Xiu de Yaxá, Yucatán como "Yaxá", de la "Crónica de Maní" como "Maní", del Códice Pérez como "Pérez", y de la obra de John L. Stephens como "Stephens" respectivamente, se revisaron las referencias del deslinde, i) del cúuchcabal de Maní con los pueblos adyacentes (renglones 1-5), ii) entre los pueblos ubicados dentro de esta entidad política (renglones 6-9), y iii) de las poblaciones particulares (renglones 10-13). Su cuadro comparativo (Figura 2) nos permite comprender cómo se elaboró cada uno de estos textos.

\begin{tabular}{|r|l|c|c|c|c|}
\hline & \multicolumn{1}{|c|}{ Deslinde con: } & 1. Yaxá & 2. Maní & 3. Pérez & 4. Stephens \\
\hline 1 & Maxcanú & $\checkmark$ & $\checkmark$ & $\checkmark$ & $\checkmark$ \\
\hline 2 & Calkiní y Bécal & $\checkmark$ & $\checkmark$ & $\checkmark$ & $\checkmark$ \\
\hline 3 & Cuzamá y Homún & $\checkmark$ & $\checkmark$ & $\checkmark$ & $\checkmark$ \\
\hline 4 & Sotuta & $\checkmark$ & $\checkmark$ & $\checkmark$ & $\checkmark$ \\
\hline 5 & Tixcacal y Hunactí & $\checkmark$ & $\checkmark$ & $\checkmark$ & $\checkmark$ \\
\hline & Deslinde entre: & & & & \\
\hline 6 & Tekax y Tzucacab & $\checkmark$ & & & \\
\hline 7 & Maní y Pencuyut & $\checkmark$ & $\checkmark$ & & \\
\hline 8 & Teabo y Pencuyut & & & $\checkmark$ & \\
\hline 9 & Ticul y Oxkutzcab & $\checkmark$ & & & \\
\hline
\end{tabular}

13. Debido al clima poco favorable de Yucatán para la conservación de los documentos, es muy probable que a partir del siglo XVII, en vez del texto original, se guardase su traslado en este Archivo. 


\begin{tabular}{|c|l|c|c|c|c|}
\hline & \multicolumn{1}{|c|}{ Deslinde $\boldsymbol{d e}:$} & 1. Yaxá & 2. Maní & 3. Pérez & 4. Stephens \\
\hline 10 & Calotmul & & & $\checkmark$ & \\
\hline 11 & Hunactí & & & $\checkmark$ & \\
\hline 12 & Pencuyut & & & $\checkmark$ & \\
\hline 13 & Tzucacab & & & $\checkmark$ & \\
\hline
\end{tabular}

Fig. 2 - Cuadro comparativo de las cuatro versiones del "Título de tierras de Maní" (CTsubasa Okoshi Harada)

Es obvio que las cuatro versiones comparten las descripciones de los tramos 1-5, es decir un "tronco común" que consiste, en realidad, en el deslinde de la jurisdicción de don Francisco de Montejo Xiu, quien ejercía su poder como halach uinic en $1557^{14}$. Consideramos que esta parte común es la que fue copiada del "Título original" guardado en el archivo de Maní. En tanto que las demás secciones corresponden al deslinde entre los pueblos o bien de los pueblos independientes, las cuales fueron preparadas después del fallecimiento de este gobernante ocurrido hacia finales de la década de 1560.

Aunadas a ello, las Reales Cédulas de composición de 1591 (y reiteradas después en 1618, 1631, 1642 y 1646, hasta fines del periodo colonial) permitieron un reordenamiento de la propiedad indígena (Menegus Bornemann 1994, p. 212-213) y estas cuatro versiones conservadas en distintos pueblos ${ }^{15}$ son una prueba de que las comunidades indígenas sí prepararon sus propios títulos y los usaron en diferentes momentos de la época colonial ${ }^{16}$. En concreto, las autoridades de los pueblos mayas acudían al archivo de Maní para consultar el "Título original" de 1557 y de ahí sacaban sus traslados. Al regresar, les agregaban datos concretos del deslinde con sus pueblos vecinos, obteniendo de tal manera sus propios "títulos primordiales".

Lo anterior señala, por una parte, que los pueblos de la desaparecida entidad política de los Xiu mantenían hasta el siglo XIX cierto lazo con su antigua capital mediante el "Título" de Francisco de Montejo Xiu. Era una costumbre generalizada acudir a este acervo documental para su consulta y el conocimiento del mismo se compartía entre numerosos pueblos de indios e inclusive entre aquellas comunidades que no dependían de los Xiu en la época prehispánica

14. Respecto al sector sureño, no hay ninguna mención de las mojoneras. Esto se debe al principio de la tenencia de la tierra y territorialidad que manejaban los mayas desde la época prehispánica. Al respecto, véase Okoshi Harada (2010, p. 507-536).

15. Al menos se sabe que una estaba en Yaxá y la otra incluida en la "Crónica de Maní" proviene de Maní. La versión recogida en el Códice Pérez probablemente estaba conservada en Calotmul. En cuanto a la que publicó Stephens estaba guardada en el Archivo de Maní (1963, p. 170-171). No obstante, no se sabe a ciencia cierta la interrelación entre ésta y la de la "Crónica de Maní".

16. Para el estudio comparativo de la formación de las cuatro textos así como sus interrelaciones, véase el trabajo de Frauke Riese (1981). 
pero colindaban con su jurisdicción. Al respecto, por ejemplo, en un pasaje del Códice de Calkiní (Okoshi Harada 2009, p. 92) se lee que hacia 1821 los representantes de Calkiní fueron a Maní para buscar:

24. ti u mapail u cahalob

25. ti noh archibo yan tiob

26. tumenel don Francisco Montejo Xiu

27. gobernador

28. uai ti le Yucatan lae el mapa de los pueblos en el gran archivo que tienen [elaborado] por don Francisco de Montejo Xiu gobernador de aquí en este Yucatán

Por otro lado, este cuadro comparativo apunta que a partir de la última década del siglo XVI el "Título" de don Francisco comenzó a funcionar de otra manera con significados distintos. Recordemos que este documento originalmente fue preparado para legitimar la jurisdicción de este gobernante dentro del régimen colonial, marcando claramente los límites territoriales de la misma. Pero luego se convirtió en un texto de consulta obligatoria para cualquier problema relacionado con el lindero de los pueblos. Ahora funcionaría como documento matriz y sería aprovechado para elaborar los títulos de los demás pueblos de indios. Es decir, de ser "Título de tierras" de la entidad política de los Xiu pasó a ser una parte sustancial de los títulos primordiales de los pueblos particulares. Desde luego, esto implicaba el cambio de su significado atribuido: de lo privativo de la casa señorial al uso comunal o colectivo de los pueblos interesados. En concreto, para las comunidades indígenas el "Título" de don Francisco era indispensable a fin de otorgar autenticidad y legitimidad a los títulos que estaban preparando, haciendo ver la antigüedad de la posesión de sus montes, remontándose hasta cuando este halach uinic regía. Así, la figura del gobernante Xiu de la filiación prehispánica también sufre un cambio adquiriendo una imagen diferente: del señor de carne y hueso se transformó en el "fundador del orden actual colonial" que en ese momento ellos vivían.

Respecto a este último, vale la pena referirse al litigio entre los pueblos de Calkiní y Nohcacab. En 1812 los del cabildo de Nohcacab acudieron al pueblo de Maní ("Crónica de Maní” MS, f. 10r):

1. utial u kat toon $u$ hahil

2. yetel u sertificasionil $u$ hahil

3. yan u kaxob

4. p'isan

5. utial u tzentic u baob

6. dzan

7. tumenel don Francisco Montejo Xiu

8. gobernador

9. uay ti cah Mani uchie con la finalidad de pedirnos

(= a la autoridad de Maní) la verdad

y el certificado de verdad

que hay sobre los montes

medidos

para que se mantengan

otorgados

por Francisco Montejo Xiu

gobernador

de aquí del pueblo de Maní antes 

10. bay xan lic alic
11. u hahil yanil
12. ychil noh mapa
13. cu yalic
14. tux $и$ xul u lum
15. ah calkiniob
16. ti u xul tiob
17. ah nohcacabob xani

\author{
Asimismo que diga \\ la verdad que hay \\ en el gran mapa \\ que habla \\ hasta dónde alcanza la tierra \\ de los de Calkiní \\ Es ahí donde les alcanza (la tierra) \\ de los de Nohcacab también.
}

La autoridad de Nohcacab consideraba la importancia de respetar y mantener lo escrito en el "Título" y lo dibujado en el mapa, puesto que los montes en litigio habían sido mensurados y concedidos por don Francisco de Montejo Xiu. En el pasaje citado este gobernante está referido como la suprema autoridad por haber determinado los linderos de esta región, lo cual a la vez está enlazado con la idea de que él y sus documentos, es decir el "Título" y el mapa, son como el origen del mundo en que vivían. De hecho, en las diligencias que se habían efectuado once años antes (1801), los representantes de Maní traían consigo “el libro y mapa antiguo del repartimiento de tierras que hizo don Francisco Montejo Xiu del año de mil quinientos cincuenta y siete (1557) de donde fue sacado el que rige en este [...]" (ibid., f. 18v). Para ellos, estos documentos jugaban un papel casi bíblico al explicar y afirmar que el origen del espacio-tiempo tuvo lugar en 1542 con la fundación de la ciudad de Mérida como sede política y administrativa de la gobernación de Yucatán.

\section{La distancia entre hoy (ahora) y ayer (pasado): otra mirada del tiempo de don Francisco de Montejo Xiu y sus sucesores}

Irónicamente, existe una probabilidad de que don Francisco de Montejo Xiu hubiera previsto las consultas de su "Título" en tiempos venideros ${ }^{17}$. Al inicio de una de las cuatro versiones se lee (Quezada y Okoshi Harada op. cit., p. 55):

1. u kahlay thoxci kaax

2. tu menob almehenob

3. yetel halach uinic

4. don Francisco de Motejo Xiu

5. governador

6. uay ti noh cah Manii lae

7. yetelix u chayanil gobernadores

8. talob ti hunhuntzuc ti cahe
Memoria de la distribución del monte [realizada] por los nobles

y el halach uinic

don Francisco de Montejo Xiu

gobernador

de aquí de este gran pueblo de Maní y sus demás gobernadores

que vinieron con sus séquitos al pueblo [de Maní]

17. Sin duda, él deseaba que perdurara la jurisdicción de la casa señorial de los Xiu durante tiempo indefinido bajo el régimen colonial. La consulta de su título en tiempos venideros, por ende, originalmente estaba pensada para reafirmar sus linderos, sin bien esto sufriría un cambio radical después de la desintegración de su entidad política, el cúuchcabal de Maní. 
Esta voz (kahlay) se traduce generalmente como "historia" (Edmonson y Bricker 1985, p. 59; Hanks 2010, p. 97) o "memoria" o "memorial" (Calepino maya de Motul en adelante CM 2001, Acuña ed. p. 319), un concepto muy vago. Edmonson y Bricker (ibid.) asientan respecto a esta voz que "el concepto maya de la historia es memorial (kahlay) que registra los eventos en orden calendárico como en kahlay katunob, cuenta de los katunes. [...] Orden es la característica central y género principal de la literatura maya."

En lugar de desarrollar la discusión con base en estas interpretaciones, valdría la pena explorar el campo semántico que tiene esta voz maya. De acuerdo con el CM (ibid., p. 318), kahal, como verbo, tiene la acepción de: "acordarse", y como sustantivo: "memoria del que se acuerda de alguno". Para reconstruir su acepción principal, revisemos los ejemplos del uso de kah, su morfema principal. Kahal ti ol quiere decir: "reconocer o conocer de vista" (ibid., p. 318), es decir, aquí resalta la relación entre lo registrado en la mente con lo que está presente. A este respecto, contamos con el verbo kaholtah: "conocer de vista y marcar algún lugar o persona para acordarse de ella" y en su forma de participio pasado kaholan tiene la acepción de: "cosa marcada, puesta en la memoria para no olvidarla" (ibid., p. 320). Es decir, el mencionado lazo de lo que está en la mente, o sea, en la memoria, con lo que está presente se hace a través de algo "marcado" para facilitar más su enlace. Asimismo, el ligar lo pasado y el presente no se hace de manera mecánica sino que implica "refrescar y avivar la memoria". Así tenemos kahcunah que quiere decir: "acordarse y traer a la memoria", y kahcunah ik: "animar, esforzar, alentar, percibir y avisar". De este último vocablo, el Calepino presenta un ejemplo de su uso: "kahcun yik a yum u p'azmal cap'el tostones ten (avisa y acuerda a tu padre que me debe dos tostones)" (ibid., p. 319). ¡Seguramente en la mente del locutor de estas palabras estaba clara la imagen de las monedas adeudadas!

Con base en lo anterior, podemos reconstruir el campo semántico del morfema kah de la manera siguiente: "refrescar la memoria a través de algún medio, con la finalidad de que el pasado registrado en la memoria cobre vida en el "presente". En la época prehispánica, ese "medio" era abundante en forma de estelas, cerámicas, códices, pinturas murales, etc. y en cuanto al caso colonial que nos concierne, fue el escrito en el que se narra el detalle del deslinde de los montes. Recordemos que el actual manuscrito del "Título" es una copia elaborada en el siglo XVIII y cuenta con tres versiones distintas, lo cual indica el profundo interés que los de Maní tenían por conservar de manera activa la memoria registrada en 1557. Para ellos, este texto no era de ninguna manera una reliquia perteneciente al pasado sino que, como lo señala el término kahlay, estaba siempre relacionado con los intereses del "presente" hasta el siglo XIX. El "Título" se convirtió en la memoria colectiva compartida por muchos pueblos de indios.

En los documentos que pueden clasificarse dentro del género de kahlay como lo proponen Edmonson, Bricker y Hanks, por ende, el pasado existe como un ente próximo al presente, o mejor dicho el pasado habría sido elaborado con la 
finalidad de que sirviera de referencia en los días venideros, para diversos "presentes" transitorios. Esto era posible, según las palabras de Nancy Farriss (1985, p. 55), porque "el código maestro empleado para interpretar la realidad presente será el que sirve también para conservar en la memoria. Tiene que ser el mismo sistema de clasificación". En la mirada de los mayas coloniales, al menos en los documentos de este género, todo pasa como si el pasado fuese el tiempo constantemente renovable además de poder ser revivido a través de los escritos en el momento de su consulta. En kahlay, por ende, siempre se encuentra el pasado sometido a la valoración cualitativa del presente de quienes lo manejaban. Se trataba de un registro del pasado pero refrescado en la mente de los que lo interpretan en el "presente".

Así la intención original de don Francisco, que consistía en elaborar un "Título" de su jurisdicción para perpetuarla bajo el régimen colonial y que sus descendientes lo consultaran una y otra vez con la finalidad de reafirmarla, fue desvaneciéndose rápidamente después de su fallecimiento y de la desintegración de la entidad política que él encabezaba. A partir de las últimas décadas del siglo XVI y en adelante, los pueblos que consultaban este documento encontraban en él otro significado otorgándole otra función en un contexto diferente. El "Título" de 1557 era EL documento en que estaba asentada LA VERDAD, la cual narraba la "creación" y por ende el "origen" del espacio-tiempo donde estaban los pueblos mayas coloniales. La imagen de don Francisco, más allá de ser legitimador y la máxima autoridad indígena en la república de indios, ahora se convertiría en el creador-fundador del orden espacial de la misma. Es justamente por ello, a través de varias reproducciones del "Título" de 1557, que su nombre permaneció en la memoria colectiva hasta el siglo XIX entre las autoridades de los pueblos de la ex-cúuchcabal de Maní así como de aquellos que colindaban con éste.

\section{Consideraciones finales}

En este trabajo nos hemos propuesto analizar aquel conjunto de las cuatro versiones del "Título de tierras de Maní" (1557) en su propio contexto histórico y se dio énfasis a su estudio diacrónico. Se demostró, por una parte, la convivencia de las dos tradiciones distintas sobre espacio-tiempo en estos textos, y por otra parte el proceso de cómo vino cambiando el significado atribuido a este "Título" a lo largo del tiempo. Esto podría expresarse simbólicamente como sigue: del "Título" individual-personal de don Francisco de Montejo Xiu al colectivo sometido al manejo entre varios pueblos de indios. Este documento se reconocería como un libro de "verdad" que otorgaba la legitimidad y autenticidad a sus subsecuentes títulos mientras que la figura de este gobernante se convirtió en la de fundador y por ende legitimador del espacio-tiempo del mundo indígena de la época colonial.

La elaboración de los títulos por los pueblos de indios implicaba crear su historia de origen o en otras palabras su propio "mito de origen". Su punto de partida temporal había sido, en nuestro caso, el "yalmah thanil ca noh ahau 
Su Majestad ah tepale (mandamiento de nuestro gran ahau, Su Majestad, el soberano)" ("Crónica de Maní" MS, f. 1r), que se refiere en realidad a las "Ordenanzas" emitidas en 1552 por el oidor Tomás López Medel, así como la toma de decisión de don Francisco de Montejo Xiu, con el fin de llevar a cabo el trazado del lindero de su jurisdicción (ibid.; Quezada y Okoshi Harada op. cit., p. 55, 56). Su contenido era nada menos que aquella sección que se refería a la extensión de la jurisdicción de este gobernante indígena, junto con la descripción detallada del proceso de la creación del nuevo espacio-tiempo.

A diferencia del mito de origen de la filiación prehispánica, en éste no se narra la cosmogonía de tipo Popol Vuh, pero de igual manera se explica quiénes participaron, cuándo y cómo se había creado el mundo en que los mayas vivían en ese entonces. El "ayer" descrito en ello marca su presencia para explicar el "ahora" cambiante y la distancia entre éstos, en realidad, siempre había sido corta, e inclusive podemos hablar de su colindancia. Cuando leemos los pasajes que invocan a don Francisco ya fallecido hace tiempo para legitimar el lindero establecido, lo confirmamos.

Esto nos hace recordar el "Árbol genealógico de la familia Xiu” (Figura 3).

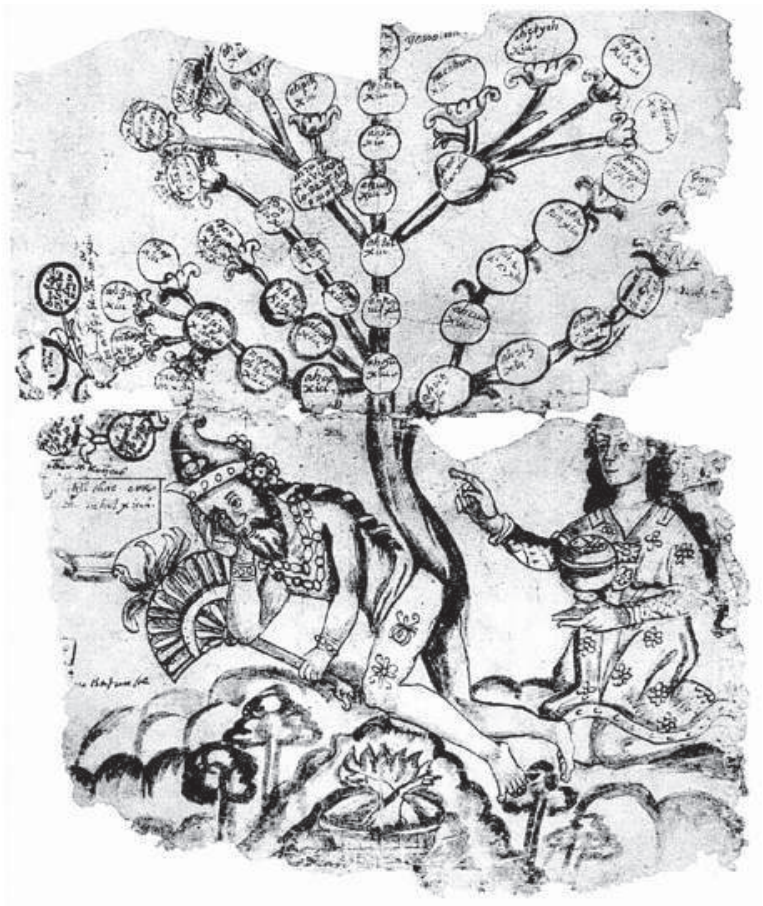

Fig. 3 - "Árbol genealógico de la familia Xiu”. Cortesía de la Biblioteca Tozzer del Museo Peabody, Universidad Harvard, EE UU. 
En este dibujo, elaborado por Gaspar Antonio Chi Xiu (ibid., p. 21-27), se aprecia la filiación de los miembros de esta casa señorial en relación con la pareja fundadora: Hun Uitzil Chac Tutul Xiu y la hija del señor de Ticul. De acuerdo con la historia de los Xiu, Hun Uitzil Chac arribó a las Tierras Bajas del norte hacia el Katún 2 Ahau (987-1007 d. C.) y se estableció en Uxmal contrayendo matrimonio con la hija del señor de Ticul (ibid., p. 37). Luego, como se aprecia en la figura 4, les siguen dos personajes, Ah Dzun Xiu y Ah Uitz Xiu, los cuales, sin embargo, no eran sus hijos, sino que eran señores del siglo XV, reconocidos como sus ancestros directos por quienes vivieron la invasión y el inicio de la dominación española.

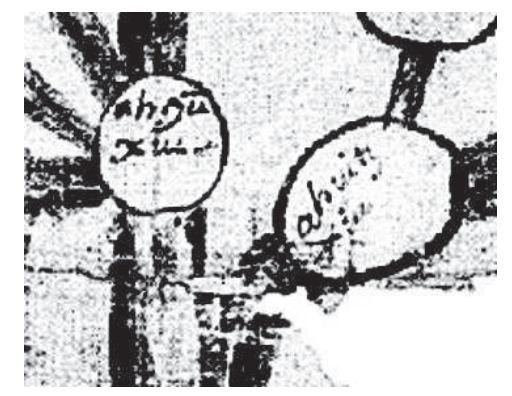

Fig. 4 - Imagen de acercamiento del "Árbol genealógico de la familia Xiu”. Cortesía de la Bibliotteca Tozzer del Museo Peabody, Universidad Harvard, EE UU.

Lo anterior indica el hecho de que entre el fundador y los de la primera generación mencionados existe una laguna de más de 400 años o de casi 18 generaciones (ibid., p. 25). Es en esta "omisión", sin duda intencional, donde podemos apreciar la noción indígena del tiempo. Es decir, en este discurso el "pasado" referente a la fundación de la casa señorial Xiu está utilizado para demostrar su descendencia lineal directa de "ahora". En este contexto no tiene importancia alguna la distancia temporal que separa a la pareja fundadora de sus descendientes de los siglos XV y XVI, pues su objetivo principal consistía en demostrar los fundamentos de manera visual para ser reconocido como "señores naturales" bajo el régimen hispano. Este "Árbol”, por ende, es un medio gráfico equivalente a kahlay para refrescar la memoria colectiva, con la finalidad de que el pasado cobrara vida en el presente.

Al término de este trabajo, bastaría decir que los mayas de la época colonial ante las políticas de "reducción", crearon su propio espacio-tiempo adoptando varios conceptos hispanos. A los ojos de la autoridad española se trataba de un logro de las mismas y no podemos negar la profunda alteración que había sufrido la sociedad maya en diversos aspectos. Pero, por otra parte, con el análisis de 
sus escritos, también podemos percatarnos de la persistencia de sus conceptos de la filiación prehispánica, la cual buscó su propio lugar para otorgar sentido al espacio-tiempo creado para convertirlo en suyo.*

* Manuscrit reçu en mars 2015, accepté pour publication en juin 2015.

Este artículo forma parte del número especial Compases y texturas del tiempo entre los mayas: lo dicho, lo escrito, lo vivido.

Agradecimientos - Agradezco a la Dra. Antoinette Molinié y al Dr. William F. Hanks por sus comentarios que enriquecieron y ampliaron mi perspectiva para ahondar mi discusión.

\section{Referencias citadas}

Acuña René (ed.)

2001 Calepino maya de Motul, Plaza y Valdés, S.A. de C.V., México.

BORAH Woodrow

1996 El Juzgado General de Indios en la Nueva España, Fondo de Cultura Económica, México.

Crónica de Maní"

MS "Fragmentos y planos del Archivo General de la Conquista desde 1557-1813", Tulane University, Latin American Library, Howard Tilton Memorial Library, New Orleans.

EDMONSON Munro S. y Victoria R. BRICKER

1985 "Yucatecan Mayan Literature", in Victoria R. Bricker (ed.), Supplement to the Handbook of Middle American Indians, 3, University of Texas Press, Austin, p. 44-63.

FARRISS Nancy

1985 "Recordando el futuro, anticipando el pasado: tiempo histórico y tiempo cósmico entre los mayas de Yucatán", in La memoria y el olvido. Segundo simposio de historia de las mentalidades, Instituto Nacional de Antropología e Historia, México, p. 47-60.

GorDON George B. (ed.)

1913 The Book of Chilam Balam of Chumayel, University of Pennsylvania, Philadelphia.

HANKS William F.

2000 [1987] "Discourse Genres in a Theory of Practice", in Intertexts. Writings on Language, Utterance, and Context, Rowman \& Littlefield Publishers, Inc., Lanham, p. 133-164.

2010 Converting Words. Maya in the Age of the Cross, University of California Press, Berkeley.

LANDA Diego de

1938 Relación de las cosas de Yucatán, E.G. Triay e Hijos Imps., Mérida (Yucatán). 
López Cogolludo Diego

1957 Historia de Yucatán, Academia Literaria, Serie "Colección de grandes obras mexicanas, 3", México.

Menegus Bornemann Margarita

1994 “Los títulos primordiales de los pueblos de indios”, Estudios, 20, p. 207-230.

OKoshi HaRada Tsubasa

2001 “Gaspar Antonio Chi Xiu: el que 'perpetuó' la imagen de los Xiu”, in Ueli Hostettler and Matthew Restall (eds), Maya Survivalism. Verlag Anton Saurwein, Germany (Acta Mesoamericana, vol. 12), p. 59-72.

2009 Códice de Calkiní, Universidad Nacional Autónoma de México, Instituto de Investigaciones Filológicas, Centro de Estudios Mayas (Serie Fuentes para el estudio de la cultura maya, 20), México.

2010 "La formación de las entidades políticas de las tierras bajas mayas del Posclásico tardío: una nueva perspectiva", in Aurore Monod Becquelin, Alain Breton y Mario Humberto Ruz (eds), Figuras mayas de la diversidad, Universidad Nacional Autónoma de México, CEPHCIS, Mérida, p. 507-536.

Quezada Sergio

1993 Pueblos y caciques yucatecos, 1550-1580, El Colegio de México, México.

Quezada Sergio y Tsubasa Oкоsнi HaRada

2001 Papeles de los Xiu de Yaxá, Yucatán, Universidad Nacional Autónoma de México, Instituto de Investigaciones Filológicas, Centro de Estudios Mayas (Serie Fuentes para el estudio de la cultura maya, $n^{\circ} 15$ ), México.

Restall Matthiew

1997 The Maya World: Yucatec Culture and Society, 1550-1850, Stanford University Press, California.

RiESE Frauke J.

1981 Indianische Landrechte in Yukatan um die Mitte des 16. Jahrhunderts. Dokumentenanalyse und Konstruktion von Wirklichkeitsmodellen am Fall des Landvertrages von Mani, Kommissionsverlag Klaus Renner, Hohenschäftlarn bei München, Hamburg.

Roys Ralph L. (ed. y trad.)

1939 The Titles of Ebtun, Carnegie Institution of Washington (Carnegie Institution of Washington Publication 505), Washington (D.C.)

1943 The Indian Background of Colonial Yucatan, Carnegie Institution of Washington (Carnegie Institution of Washington Publication 548), Washington (D.C).

RuBio MAÑÉ Jorge Ignacio

1945 "Reseña histórica de Yucatán”, in Catálogo de construcciones religiosas del Estado de Yucatán, Secretaría de Hacienda y Crédito Público, Dirección General de Bienes Nacionales, México, p. xxxi-liii.

Solís Alcalá Ermilo (trad.)

1949 Códice Pérez, Liga de Acción Social, Mérida (Yucatán).

Stephens John L.

1963 The Incidents of Travel in Yucatan, Dover Publications, Inc., New York, 2 vol. 